\title{
Critical Construction Work Items for Sustainable Hospitals
}

\author{
Claudia Valderrama-Ulloa ${ }^{1}$, Pablo Canales ${ }^{2}$ and Ximena Ferrada ${ }^{3}$
}

1 Pontificia Universidad Católica de Chile, Santiago, Chile, c.valderrama@uc.cl

2 Ministerio de Salud, Santiago, Chile, pablo.canales@minsal.cl

3 Universidad del Desarrollo, Santiago, Chile, ximenaferrada@udd.cl

\begin{abstract}
Currently, the Chilean public health infrastructure presents significant advances in the implementation of sustainable design criteria, with the incorporation of these criteria in the architecture and speciality projects. However, it is possible to observe that during the construction phase of the project there are no standardized verification processes of the project guidelines in these aspects, which could affect the sustainable life cycle of these buildings. Errors in the execution of critical health infrastructure items have various consequences during their operation, such as excessive corrective maintenance, increased in public spending for additional energy requirements from the systems, or discomfort of building occupants (overheating or over-cooling problems). Besides, the technical inspection of public works in Chile focuses mainly on the administrative fulfilment of construction contracts rather than on the verification of the technical aspects of projects. This problem establishes the need to analyze the critical items that must be verified on-site to ensure that the sustainability criteria delivered during the design stage are executed correctly, allowing a sustainable operation of these buildings over time. Then, this research focused on determining what the critical items and activities that should be reviewed on-site, as well as on detecting the possible weaknesses of the project review process are. A survey to professionals involved in the design, construction and inspection of hospital infrastructure was applied. The results were analyzed using the AHP methodology, showing as critical items the thermal envelope (20\%) and the thermal and ventilation installations (17\%). At the activity level, there was no significant consensus on the most relevant to the review process. There are also differences in the vision of engineers and architects regarding some issues. Finally, the need to have technical regulations that provide procedures and control standards for each item, system and installation from early design phases was identified.
\end{abstract}

(c) 2020 The Authors. Published by Budapest University of Technology and Economics \& Diamond Congress Ltd Peer-review under responsibility of the Scientific Committee of the Creative Construction Conference 2020.

Keywords: public health infrastructure, sustainability, sustainable buildings

\section{Introduction}

Currently, the public health infrastructure presents essential advances in determining sustainability design criteria, which are reflected in the development of architecture and speciality projects. The incorporation of these criteria arises in the mid-2000s, due to the State's drive to include energy efficiency in public infrastructure as a response to international commitments regarding climate change [1]. However, it is possible to observe that during the construction phase of the public health infrastructure, there are no standardized verification processes of the project guidelines regarding sustainability, which could affect the sustainable life cycle of these buildings. Mistakes in the execution of critical items in the health infrastructure have various consequences during the operation of a building, from excessive corrective maintenance and increased public spending for extra energy, to environmental discomfort for the people who use the building (overheating or over-cooling problems). [2] 
For their part, Technical Inspection of public works in Chile focuses on the administrative compliance of construction contracts rather than on the verification of the technical aspects of the projects. A study by the Office of the Comptroller General of the Republic [3] indicates that the most relevant observation in public health work contracts is the failure to comply with technical aspects. In contrast, other academic studies verify that the flaws in the design processes are the main factor that affects the problems that are triggered in the works [4]. This problem reflects the need to have protocols and construction standards incorporated from the beginning, at the design stage and accompanied by a technical inspection of work focused on the correct functionality of the characteristics of the systems and facilities in hospital establishments. The research focuses on a survey carried out on professionals who participate in the design, construction and supervision of hospital works. The results are analyzed with the AHP methodology to rank the critical items and the critical activities and also detect the possible weaknesses that these professionals observe in their work.

\section{Methodology}

The present study has been divided into two stages. In the first stage, a summary and analysis of the context of hospital establishments in Chile are presented, to understand how they manage the design, tender and construction phases, deepening in the processes related to the technical inspection of works. This stage ends with the presentation of the minimum design requirements needed for energy efficiency and sustainability in operation in Hospitals. This information is the basis for identifying the critical items that need to be reviewed in the execution stage of hospital centres in Chile. In the second stage, the critical items are selected through a survey applied to different experts in the area. The results were analyzed using a multi-criteria prioritization method (AHP).

\section{MINSAL's role in public health building}

The Chilean Ministry of Health (MINSAL) has within its functions to set the policies and regulations for investment in infrastructure and equipment of the public establishments that make up the healthcare networks [5]. For such purposes, the Under secretariat of Assistance Networks oversees regulating and supervising the operation of health networks through the design of policies, regulations, plans and programs for their coordination and articulation. Within this undersecretary, a division manages the resources available to finance initiatives in infrastructure and health equipment. Each project or action must comply with all the regulatory requirements that emanate from the MINSAL regarding sanitary provisions, quality of care and user satisfaction. In this sense, MINSAL is responsible for generating investment plans in health infrastructure, as well as the criteria and guidelines with which the designs, construction and operation of new health facilities, will be developed.

\section{Hospital establishments}

Hospitals correspond to closed care establishments, which provide health benefits in a continuous care regime ( 24 hours) and which must have organized resources of infrastructure, equipment, and personnel necessary for their permanent operation. Hospitals provide comprehensive, general, and/or specialized care, aimed at providing health benefits for the recovery, rehabilitation and palliative care of sick people and are empowered to admit patients with bed occupancy. Currently, hospital establishments are configured with an ambulatory care area attached (medical consultations, procedure rooms, therapeutic, diagnostic support units, and emergency) and complementary to closed care where hospitalizations are mainly located. In Chile, hospitals are highly relevant to meet the health care needs of the population. However, the national health infrastructure is in a deficit situation, which is evidenced by the lack of hospital beds by the number of inhabitants. This situation has generated, in the last decade, the development of investment plans in hospital infrastructure that allow strengthening the existing healthcare network. Despite the efforts made, the latest diagnosis carried out in 2018 indicates that $80 \%$ of hospitals still fail to comply with the current infrastructure quality standard, due to the age of their buildings and $63 \%$ of facilities have a structure before the 80s [6]. 


\subsection{Design and execution process of hospital works}

The development of Health projects is carried out through public bidding under different types of contract and work. This type of contract generates a close collaboration between the public sector (Ministry of Health), manager of the initiatives, and the private sector (Consulting, Architecture, Engineering and Construction Companies) in the planning, programming, preparation of preliminary projects and development of the projects, both low and high level of medical and technological complexity of establishments. The plans go through the following stages from the investment idea to the operation:

- Hospital Pre-investment Study: it defines the number of atributes that the establishment will offer, the number and size of the facilities, the management model, human resources, medical equipment, and financial sustainability. Besides, during this stage, the site is selected.

- Design: the Pre-project sub-stage is carried out, in which architecture is defined at a basic level of development as well as the design criteria of the corresponding specialities. Also, the Project substage is carried out, where the design of architecture and specialities is developed at a level suitable for execution. Products include detailed engineering and planimetry, technical specifications and BIM modelling.

- Execution: During this stage, the designated construction company executes the works according to the approved in the design, planimetry and technical specifications of architecture and specialities and the provisions of the contract.

\subsection{Technical inspection of public hospitals}

In Chile, there is no detailed procedure for the inspection of hospital works. Although there is a Technical Works Inspection Manual [7], its scope is aimed at the inspection of social housing and its items, extending overtime to paving projects and green areas [3].

Thus, a study on observations and recommendations in the execution of public works contracts carried out by the Comptroller General of the Republic between 2012 and 2015, showed that a large part of these observations is directly related to the role of the technical inspection of works, highlighting non-compliance with technical regulations (27\%). Compliance with technical regulations groups together all the relevant observations associated with breaches of both the technical bases, be they technical specifications, plans and/or memories of structural calculation, as well as existing regulations applicable to the contract, such as the Chilean INN Standards, the Roads Manual of the MOP, the General Law of Urbanism and Constructions, and its ordinance, and in the case of health, special regulations for hospital infrastructure buildings such as the Basic Technical Standards for Closed and Open Care [3]. The same study shows that $51 \%$ of the works observed have a relationship with health establishments. On the other hand, Moscoso [3] indicates that public hospital projects, generated inside the traditional contracting system, do not include the technical inspector in early design stages, which is why two main problems arise. First, activities are generated that do not add value. Since the technical inspector is hired or assigned at the start of the work, he must invest time in studying the project and all the administrative documents that are part of the work. Second, the contribution and experience that the technical inspector can deliver in the early stages of the project, where any modification has a minor impact on its costs, is wasted.

Another study on Technical Inspection of Works indicated that above the typical problems that construction works present, there are a significant number of facts and situations that give rise to conflicts and doubts, not always attributable to a wrong decision by the owner or poor management of the contractor. These conflicts usually have their origin in some of the following causes: projects that do not have an adequate level of detail, which prevents defining with precision and objectivity, the requirements and standards that must be verified by the technical inspector; the parent projects do not have efficient coordination among themselves or with the specialities; the roles and responsibilities that the different agents of the constructive process must assume to varying stages of the projects are not appreciated; analysis and evaluations, essential for adequate and timely decision-making, must be based on uncoordinated and 
unreliable records; and the indetermination, omissions and errors that the administrative bases of the contracts present, give rise to a significant number of conflicts in the relationship between the parties.

\subsection{Sustainable construction in public hospitals}

Since the mid-2000s, the Chilean Ministry of Health has incorporated sustainability criteria in the designs of health facilities. The first efforts around sustainability are focused on energy efficiency, establishing envelope specifications (walls and windows) with better thermal behaviour. It reduces energy demands for the thermal conditioning of the enclosures, as well as the incorporation of more efficient active systems (air conditioning and lighting systems). Since 2010, the Chilean government the planning of new infrastructure because of the earthquake of February 27 of that same year. This reconstruction focused on a series of establishments with structural damage in the areas affected by the earthquake. Currently, the concept of sustainability has been attempted to incorporate in the designs of health establishments in a comprehensive way, recognizing the social, economic, and cultural fields.

The sustainability attributes of hospital establishments, addressed during the design, need to be audited and finally operated in the way they were projected. In this way, the initial sustainable objectives will be achieved. The proper functioning of the systems and facilities is relevant, by scheduling the correct management of maintenance and operation of these throughout the useful life of the building. Following the above, the main critical items that must be audited during the execution of a hospital project should be at least: Envelope; Acoustic Insulation; Finishing; Sanitary Facilities; Lighting and Electrical Installations; Thermal and Ventilation Installations; Non-Conventional Renewable Energy Systems, Landscaping and Waste Management.

\section{Multi-Criteria Analytic Hierarchy Process (AHP) methodology}

In this process, a weight (wi) is calculated for each alternative, making a two-by-two comparison of all the criteria. The method that has been chosen is the Analytic Hierarchy Process (AHP) of Saaty [8] due to its high popularity to determine the prioritization in varied problems such as politics, social aspects, personal desires, education, industry or engineering [9]. The AHP uses an underlying scale with values from 1 to 9 to rate the relative preferences of the two elements, being 9 an extremely preferable preference and 1 a neutral preference between the two pairs. With these values, a square matrix $[A]$ is obtained that contains paired comparisons of alternatives or criteria.

$A$ is said to be a matrix of paired comparisons of $n$ alternatives if $a_{i j}$ is the measure of the preference of the alternative in row $i$ when compared to the alternative in column $j$. When $i=j$, the value of $a_{i j}$ will be equal to 1 since the alternative is being compared with itself. Then, to determine whether or not a consistency level is "reasonable," we need to develop a quantifiable measure for the comparison matrix Anxn (where $n$ is the number of alternatives to be compared). It is known that if matrix $A$ is perfectly consistent, it produces a normalized matrix Nnxn of elements $w_{i j}$ (for $i, j=1,2, \ldots, n$ ), such that all columns are identical, that is, $w_{12}$ $=w_{13}=\ldots=w_{1 n}=w_{1} ; w_{21}=w_{23}=\ldots=w_{2 n}=w_{2} ; w_{n 1}=w_{n 2}=\ldots=w_{n n}=w_{n}$.

It is then concluded that the corresponding comparison matrix A can be determined from $\mathrm{N}$, dividing the elements of column $i$ by wi (which is the inverse process of determining $N$ from $A$ ). This is how the consistency ratio $(\mathrm{CR}=\mathrm{Cl} / \mathrm{RCl})$ is calculated. This ratio or quotient is designed such that values exceeding 0.20 are a sign of inconsistent judgments. CR values of 0.10 or less are a sign of a reasonable level of consistency in paired comparisons. In contrast, values between 0.10 to 0.20 are moderately consistent since in the value judgment, some alternatives have the same degree of importance for the evaluator. In these cases, the decision-maker is likely to want to reconsider and modify the original values of the matrix of paired comparisons. For its part, the $\mathrm{Cl}$ value is the consistency index of the matrix $\mathrm{A}=(\lambda \max -n) /(n-1)$, where $\mathrm{n}$ is the number of alternatives and $\lambda \max$ is obtained by calculating the vector column $A$ and then adding its elements. $\mathrm{RCl}$ is the random consistency index of $A=1.98(n-2) / n$, with $n$ being the number of alternatives. 


\section{Analysis of responses}

To obtain a hierarchy of the items (E: Envelope; Al: Acoustic Insulation; F: Finishing; SF: Sanitary Facilities; LEI: Lighting and Electrical Installations; TVI: Thermal and Ventilation Installations; REn: Non-Conventional Renewable Energy Systems, L: Landscaping and WM: Waste Management) that must be inspected on a hospital to ensure the sustainability of the building in operation, experts from the design and technical inspection of health establishments were surveyed. The group of experts was selected considering experience in the design and monitoring of health projects of at least 5 years, and direct involvement in the technical inspection of works in establishments currently under construction. The professionals consulted were 9 architects and 7 engineers with experience in design and monitoring of hospital establishment projects, as well as 10 technical inspectors with direct experience in technical inspection of public hospital establishments in execution.

Regarding the hierarchy of the items to be audited during construction to meet sustainability requirements in the operation stage, preference of $20 \%$ is observed for the envelope, followed by Thermal and Ventilation Installations with $17 \%$ and then Finishings and Non-Conventional Renewable Energy Systems with 13\%, hence the consistency was 0.20 . Finally, the three least voted elements were Landscaping, Acoustic Insulation and Waste Management with 7\%,6\% and 5\% (Table 1).

Table 1: Hierarchy of each item to be audited in the construction stage to ensure that the occupation/exploitation of the building complies with sustainable standards - Source: Own Elaboration

\begin{tabular}{|c|c|c|c|c|c|c|c|c|c|c|}
\hline Hierarchy & & & $E>T V$ & $\mathrm{REn}>\mathrm{LE}$ & $\bar{F}>\mathrm{L}>\mathrm{Al}>$ & & & & & \\
\hline $\begin{array}{l}\text { Construction } \\
\text { ítem }\end{array}$ & $E$ & $\mathrm{Al}$ & $\mathrm{F}$ & SF & LEI & TVI & REn & $\mathrm{L}$ & WM & $w_{i}(\%)$ \\
\hline $\mathrm{E}$ & 1 & 4 & 3 & 3 & 3 & 3 & 2 & 1 & 2 & 20 \\
\hline $\mathrm{Al}$ & $1 / 4$ & 1 & $1 / 4$ & $1 / 2$ & $1 / 4$ & $1 / 4$ & $1 / 4$ & 4 & 1 & 6 \\
\hline $\mathrm{F}$ & $1 / 3$ & 4 & 1 & 7 & $1 / 4$ & $1 / 3$ & $1 / 3$ & 3 & 3 & 13 \\
\hline SF & $1 / 3$ & 2 & $1 / 7$ & 1 & $1 / 3$ & 1 & 1 & 3 & 4 & 10 \\
\hline LEI & $1 / 3$ & 4 & 4 & 3 & 1 & $1 / 3$ & $1 / 3$ & 1 & 2 & 11 \\
\hline TVI & $1 / 3$ & 4 & 3 & 1 & 3 & 1 & 3 & 3 & 3 & 17 \\
\hline REn & $1 / 2$ & 4 & 3 & 1 & 3 & $1 / 3$ & 1 & 1 & 4 & 13 \\
\hline $\mathrm{L}$ & 1 & $1 / 4$ & $1 / 3$ & $1 / 3$ & 1 & $1 / 3$ & 1 & 1 & 1 & 7 \\
\hline WM & $1 / 2$ & 1 & $1 / 3$ & $1 / 4$ & $1 / 2$ & $1 / 3$ & $1 / 4$ & 1 & 1 & 5 \\
\hline$\lambda \max$ & 11.47 & $\mathrm{Cl}$ & 0.31 & $\mathrm{RCl}$ & 1.54 & CR & 0.20 & & & \\
\hline
\end{tabular}

The responses regarding prioritization of the audited activities in the envelope (the item with the highest priority) were separated into two groups. The first group was the suggestions made by the architects and, the second group was the items suggested by engineers and technical inspectors (see Fig. 1), which explains the significant difference in terms of the priorities indicated by each group.

For the group of architects, the priority in the 3 most voted activities was Roofing insulation (25\%), thermal enclosure insulation (15\%) and Windows (14\%). In the envelope activities audit, the 3 most voted activities by the group of engineers and technical inspectors were thermal enclosure insulation (26\%), Vapor and Humidity Barrier (16\%) and Ventilated Floors Insulation or Roofing insulation (15\%). Thermal bridge sun protection windows 


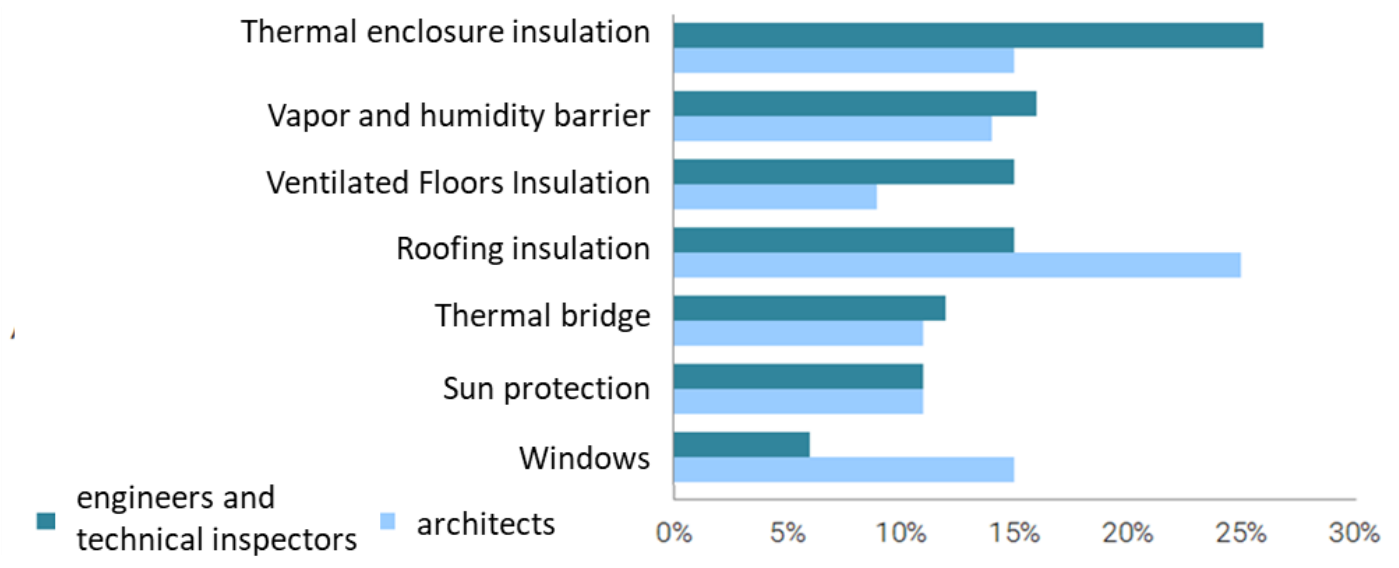

Fig. 1: Prioritization of professional regarding the activities of the enveloping item - Own elaboration

\section{Conclusion}

MINSAL is currently developing an extensive investment plan in health infrastructure, which considers the construction of 75 new hospitals for the country. Thus, it poses a significant challenge for the health sector to build this new infrastructure under sustainability parameters and to maintain it properly during its operation. Depending on the type of execution contract, the flow of information between the different phases may be hindered, because diverse teams carry out the design, construction and audits in each of them. Besides, These audits are developed in an independent way and without the proper follow-up. Due to the complexity that characterizes health facilities, continuous verification processes are required at all stages to ensure the operation of the projected systems and facilities and, therefore, established sustainability requirements.

On the other hand, the process of surveying experts and then identify through the AHP methodology their opinion regarding critical items to be inspected in hospital works allowed verifying the relevance of each critical element. It was found that the items that should be of most significant concern were the Thermal Envelope (20\%), and the Thermal Installations and Ventilation (17\%). The answers to the surveys also show the need for technical regulations in Chile that provide procedures and standards for the inspection of systems and facilities. It is necessary to develop coordinated and better quality projects from the design phase. The contribution of a specialized professional at the early stages of the design is also recognized.

\section{References}

[1] Ministry of Health (MINSAL) - Government of Chile. "Orientaciones Técnicas Para Diseño de Anteproyectos de Hospitales Complejos". Chile: MINSAL.Internal document working. (2019)

[2] F., Ascione, N., Bianco, R., F., De Masib, G., P., Vanoli. "Rehabilitation of the building envelope of hospitals: Achievable energy savings and microclimatic control on varying the HVAC systems in Mediterranean climates". Energy and Buildings, nr 60, pp. 125138. (2013). https://doi.org/10.1016/j.enbuild.2013.01.021

[3] P. Moscoso, "Estudio base para el desarrollo de una metodología de inspección técnica de obras hospitalarias", Santiago, Chile: McS Thesis. Pontificia Universidad Católica de Chile (2017)

[4] F. M., Arain, S., Assaf, L., S., Pheng, L. S. "Causes of discrepancies between design and construction". Architectural Science Review, tom 47, nr 3, pp. 237-249. (2004), https://doi.org/10.1080/00038628.2000.9697530

[5] Ministry of Health (MINSAL) - Government of Chile. "Subsecretaría de Redes Asistenciales Resolución N¹60", 184p. 2015 In: https://www.minsal.cl/sites/default/files/Orientaciones_red_2015.pdf [accessed may 2020]

[6] La Tercera. La obsolescencia de la red pública hospitalaria. (2008) In: https://www.latercera.com/nacional/noticia/la-obsolescenciala-red-publica-hospitalaria/260412/ [accessed April 2020]

[7] Ministry of housing (MINVU) - Government of Chile. "Technical Works Inspection Manual", 215p. 2007 In: https://www.minvu.cl/wpcontent/uploads/2019/05/DS_N_85_Manual_ITO_2007.pdf [accessed April 2020]

[8] T. L. Saaty, "Relative measurement and its generalization in decision making why pairwise comparisons are central in mathematics for the measurement of intangible factors the analytic hierarchy/network process" Revista de la Real Academia de Ciencias Exactas, Fisicas y Naturales. Serie A. Matematicas, tom 102, nr 2, pp. 251-318, 2008. https://doi.org/10.1007/BF03191825

[9] O. S., Vaidya, S. Kumar. "Analytic hierarchy process: An overview of applications" European Journal of Operational Research, tom 169, nr 1, pp. 1-29, 2006. https://doi.org/10.1016/j.ejor.2004.04.028 